\title{
Design criteria and performance parameters of an $\alpha$ irradiation device for cell studies
}

\author{
H Roos and A M Kellerer \\ Institut für Medizinische Strahlenkunde der Universität Würzburg, Versbacher Str. 5, \\ D-8700 Würzburg, Federal Republic of Germany
}

Received 21 March 1989, in final form 5 June 1989

\begin{abstract}
An $\alpha$ irradiation device is described that utilises a commercially available disc-shaped americium-241 source of $8 \mathrm{~cm}$ diameter. The $\alpha$ particles traverse a moving collimator and the source is rotated to reduce the influence of source inhomogeneities. Source, collimator and a shutter disc are mounted in a container which is flushed with helium to reduce energy losses of the $\alpha$ particles before reaching the exit foil. The shutter disc is activated by a computer-controlled step motor. The broad beam of $\alpha$ particles emerges from the exit window of the container with a remaining range in tissue of about $15 \mu \mathrm{m}$. An intermittent computer-controlled use of a preabsorber makes it possible to reduce dose differences within a depth up to $12.5 \mu \mathrm{m}$ to not more than $\pm 3 \%$. With the commercially available americium sources a dose rate of $0.2 \mathrm{~Gy} \mathrm{~min}^{-1}$ is reached; this can be increased by utilising a somewhat wider collimator.
\end{abstract}

\section{Introduction}

Studies with $\alpha$ emitters have long played an important role in radiobiological investigations. Early studies on the inactivation of bacteria have been performed by Lea et al (1936) and on yeast by Elkind and Beam (1955). Barendsen and Beusker (1960) and Barendsen et al (1963) and a number of other authors (e.g. Hall et al 1972, Raju et al 1975) later studied inactivation of mammalian cells. In recent years important studies of $\alpha$ ray induced mutations have been performed (Edwards et al 1980, Thacker et al 1982) and there has been special interest recently in the utilisation of $\alpha$ rays in the transformation of mammalian cells (Lloyd et al 1979, Robertson et al 1983, Hieber et al 1987). The ionisation density of $\alpha$ particles with their energy of a few $\mathrm{MeV}$ is somewhat larger than that of recoil particles produced by fast neutrons, but it is not much higher than the LET of roughly $120 \mathrm{keV} \mathrm{\mu} \mathrm{m}^{-1}$ which appears to damage cells with maximum efficiency. The convenience of a comparatively simple and continuously available device can frequently outweigh the advantages of accelerators which produce different particles with different energies. The inherent limitation of any $\alpha$ irradiator is, however, the short range of the particles and the resultant restriction to studies with viruses, bacteria or monolayers of higher cells. Even in these applications the range and the variations of absorbed dose with depth can be critical and they deserve therefore a careful examination.

Three criteria are of special importance in the design of an $\alpha$ irradiation device. First, the fluence must be reasonably uniform over an extended sample. Second, the energy must be sufficient for penetration of a monolayer of mammalian cells, and finally the absorbed dose must not vary substantially with depth in the irradiated sample. To meet the first condition, one could use a sufficiently large uniform source. Its diameter would have to be appreciably larger than that of the sample. However, 
an extended source in close proximity of the sample would contribute a large fraction of particles which enter the sample obliquely and cause a sharp decrease of the dose with depth. Although such studies have led to valuable results (Lücke-Huhle et al 1982), they pose evident problems of interpretation.

A method that avoids this complication would be to separate the source and the sample by a sufficiently large distance. However, this requires greatly reduced pressure between source and sample and would therefore necessitate-in the usual case where the biological samples may not be exposed to vacuum-an exit window with sufficient strength to support the pressure difference.

Balancing the variety of constraints one may conclude that a third solution which employs a moving collimator is most appropriate. Source and collimator are mounted in a container that is flushed with helium under normal pressure; compared with air this reduces the energy losses by a factor in excess of 5 . The foil of the exit window can be thin since it is not required to support any pressure differences. The detailed design of the irradiator and its main characteristics will be described below.

\section{Material and methods}

\subsection{Containment}

The integral parts of the instrument, source, collimator and shutter disc are mounted in a vacuum-tight stainless steel container of height $135 \mathrm{~mm}$ and diameter $400 \mathrm{~mm}$ (see figure 1). The electric motors driving the source turntable and the collimator and the step motor operating the shutter are positioned outside the container; the shafts are sealed by radial packing rings. The receptacle is flushed with helium under normal pressure. The resulting energy loss of the $\alpha$ particles at $4 \mathrm{MeV}$ is $19 \mathrm{keV} \mathrm{mm}^{-1}$; the corresponding value for air would be $101 \mathrm{keV} \mathrm{mm}^{-1}$. The gas flow is monitored by a

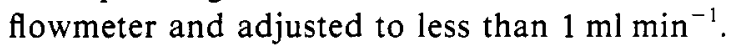

\subsection{Sample support}

The part of the container that carries the exit foil is exchangeable and has a somewhat different shape for different types of experiments. Figure 2 represents two typical designs that are utilised for studies with bacteria and for studies with mammalian cell cultures.
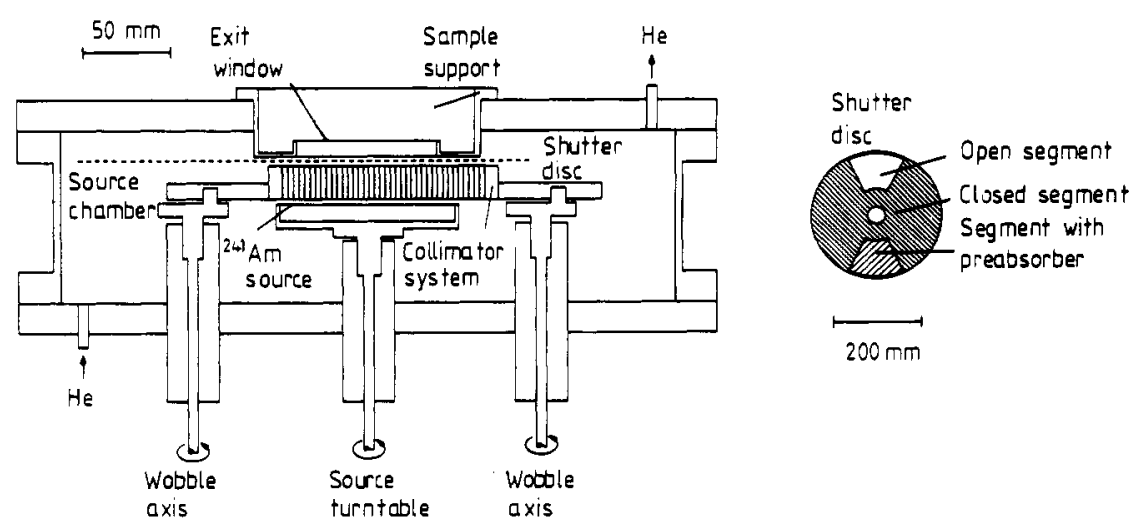

Figure 1. Diagram of the $\alpha$ irradiation device. 

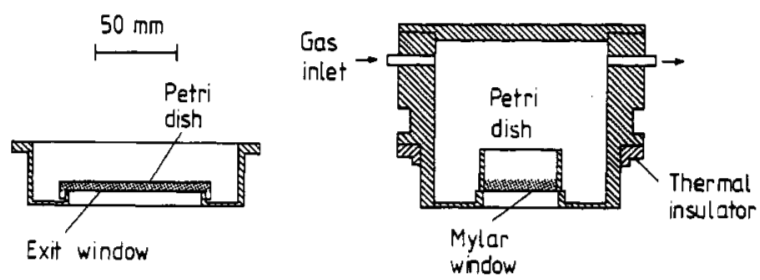

Figure 2. Left: mylar exit window designed for the irradiation of Petri dishes which are positioned upside down at the window. Right: temperature-regulated incubation chamber: mylar window separating the source chamber from the incubation chamber; also shown are the thermal insulator, gas inlet and Petri dish with foil bottom.

The left-hand diagram shows the simpler support which fits standard $85 \mathrm{~mm}$ Petri dishes in reversed position so that the bacteria on top of the agar layer are positioned upside down in close proximity (about $1 \mathrm{~mm}$ ) of the exit foil. The right-hand diagram shows the design which is an integral part of a temperature-controlled exposure chamber for cell cultures. The cells are attached to the $2 \mu \mathrm{m}$ mylar foil that forms the bottom of special Petri dishes of inner diameter of $45 \mathrm{~mm}$. The Petri dishes are filled with $8 \mathrm{ml}$ of nutrient broth and their foil bottom is in direct contact with the foil of the exit window. The temperature-controlled chamber has thick aluminium walls to facilitate temperature control through an integrated heating element. Thermal insulation between the walls of the incubation chamber and the source chamber is achieved by a plastic insulator. To stabilise $\mathrm{pH}$ the incubation chamber is connected to a gas flow system.

\subsection{Source}

The americium-241 $\alpha$ source was produced by the Radiochemical Centre Amersham (Amersham, UK). The diameter of the disc-shaped active area is $85 \mathrm{~mm}$; the americium241 has a total activity of $0.37 \mathrm{GBq}$ and is covered by $2 \mu \mathrm{m}$ of gold-palladium alloy. The half-life of americium-241 is 458 years; $85 \%$ of the $\alpha$ particles have energy $5.49 \mathrm{MeV}$, almost all of the remainder $5.44 \mathrm{MeV}$. The accompanying $\gamma$ rays $(0.4 \%$ of the decay energy) have a dominant line at roughly $60 \mathrm{keV}$; the absorbed dose rate due to the $\gamma$ rays at the sample is less than $10^{-4}$ of the dose rate due to $\alpha$ rays. As a result of self-absorption there is a distribution of energies even for those $\alpha$ particles that leave the source normally. The most probable energy of these particles is roughly $4 \mathrm{MeV}$. The thin source sheet is attached to a stainless steel disc of height $5 \mathrm{~mm}$ and diameter $87 \mathrm{~mm}$.

Measured over a spot of $6 \mathrm{~mm}^{2}$ area there are maximum differences of intensity over the surface of the source of about $\pm 20 \%$. To reduce the influence of these appreciable inhomogeneities the source is mounted on a turntable and rotated about 5 cycles per second. The rotation of the source reduces the maximum differences measured on the same spot size to less than $\pm 3 \%$.

\subsection{Collimator}

The collimator removes $\alpha$ particles that leave the source obliquely; this avoids a sharp decrease of absorbed dose with depth in the irradiated sample. The aluminium collimator disc has a diameter of $150 \mathrm{~mm}$ and a height of $15 \mathrm{~mm}$. The channels of 
$3 \mathrm{~mm}$ diameter are arranged in a hexagonal pattern with $3.2 \mathrm{~mm}$ spacing of the axes of adjacent channels (figure 3 ). The collimator restricts the $\alpha$ particles to an angle of less than $12^{\circ}$ from the normal; the transparency is $80 \%$.

\subsection{Achievement of uniform fluence}

The distribution of fluence emerging from the exit window was calculated for different distances between collimator and exit window. In these calculations a uniform distribution of the activity in the plane below the collimator was assumed. The fluence distribution is obtained as a superposition of distributions due to the individual channels. Examples of the resulting fluence distributions are represented in the diagrams of figure 4; the maximal deviations of the fluence from its mean value can be read from figure 5 . One concludes that even without movement of the collimator

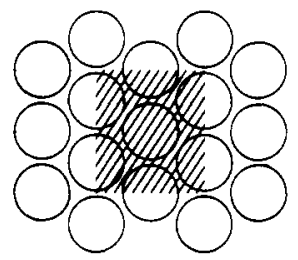

Figure 3. Hexagonal pattern of the collimator channels with channel diameter $3 \mathrm{~mm}$ and distance of adjacent channel axes $3.2 \mathrm{~mm}$. The distribution of the fluence within the shaded area is represented in figure 4 .

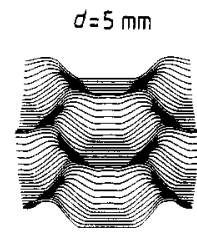

$(0.71-1.42)$

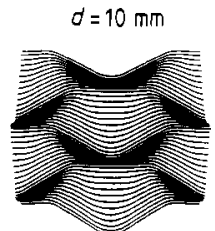

$(0.68-1.17)$

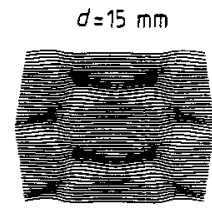

$(0.98-1.03)$

Figure 4. Diagrams of the distribution of the $\alpha$ particle fluence in the exposure plane for different distances from the collimator. The profiles are represented in central perspective. The field of $5.5 \times 6.2 \mathrm{~mm}$ is centred at the axis of a channel and corresponds to the shaded area in figure 3 . For correct visualisation one must note that the fluence is lowest at the location under the centre of the channel.

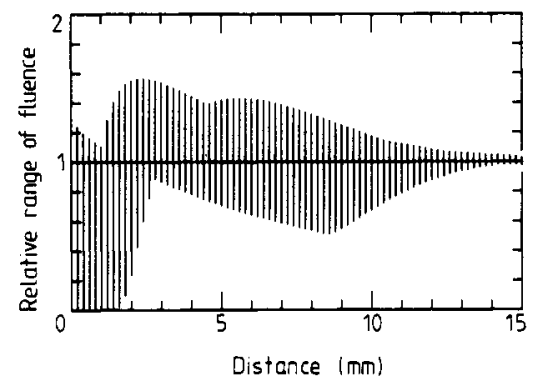

Figure 5. Relative range of fluence in a plane parallel to the collimator against distance between collimator and plane. The fluence is scaled to its mean value. 
one would achieve a high uniformity of fluence with a spacing of about $15 \mathrm{~mm}$ between collimator and exit window.

To guarantee an even higher uniformity of fluence the collimator is given circular motion without rotation. This is effected by two supports that undergo synchronous circular movement (see figure 1). The wobbling frequency is variable, with a typical value of several rotations per second. The radius of the circular movement is variable; its optimal adjustment to the collimator geometry will be considered next.

\subsection{Adjustment of the collimator movement}

The computation of the fluence profiles resulting with wobbled collimator merely requires, as is readily shown, the averaging of the fluence values over a circular path. Figure 6 gives the maximal deviations from the average fluence as a function of the wobble radius for different spacings between collimator and exit foil. One notes a considerable further reduction of non-uniformities owing to the movement of the collimator. At least for a perfectly uniform source, the collimator movement may appear unnecessary. However, it was felt that the collimator movement can be a useful feature if less uniform sources or smaller distances between collimator and exit window are used in certain applications.

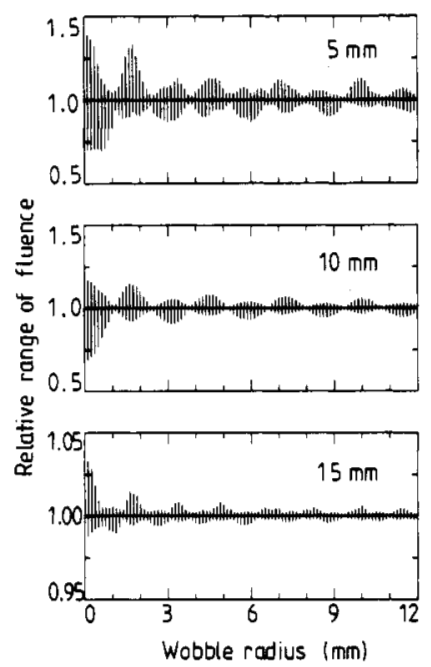

Figure 6. Relative range of fluence in a plane parallel to the collimator (at distances 5,10 and $15 \mathrm{~mm}$ ) as a function of the wobble radius. The fluence is scaled to its mean value.

\subsection{Shutter disc}

A disc-like shutter foil is localised between collimator and exit window (see figure 1). It is operated by a computer-controlled step motor that can be programmed for any desired temporal pattern of exposure. The position of the shutter is monitored by a photoelectric relay. The shutter disc contains an open section and in addition a secondary opening that is covered by an $8 \mu \mathrm{m}$ mylar foil. Intermittent exposure through the two shutter segments can be programmed in such a way that variations of absorbed dose in depth are largely compensated (see $\$ 3.4$.). 
To approximate continued exposures with specified dose rate the desired total dose and total exposure time are entered into the computer and a suitable mode of hyperfractionation is then used throughout the exposure time. In typical settings the dose per microfraction is sufficiently small that no multiple events occur in the cell; the microf ractionation can then be considered as equivalent to a continual exposure. For fractionation experiments the size and timing of individual fractions can be specified to a desired value.

\section{Resulting exposure parameters}

\subsection{Distribution of fluence in particle energy}

Figure 7 shows the distribution of fluence in energy of the $\alpha$ particles when they emerge from the exit window (full curve) and after they have traversed the added mylar bottom of a culture dish (dotted curve). A semiconductor detector was used to determine the spectra; the count rates were reduced by limiting the beam to a $1 \mathrm{~mm}$ orifice. The most probable energy of the beam is $3.1 \mathrm{MeV}$ after the exit window and 2.7 MeV after the added bottom foil. The spectra suggest that there is no substantial contribution of scattered $\alpha$ particles. On the basis of the measured energy distributions of fluence the main characteristics of the radiation field, such as the depth dependence of total fluence, of absorbed dose, and of dose-averaged LET, were calculated.

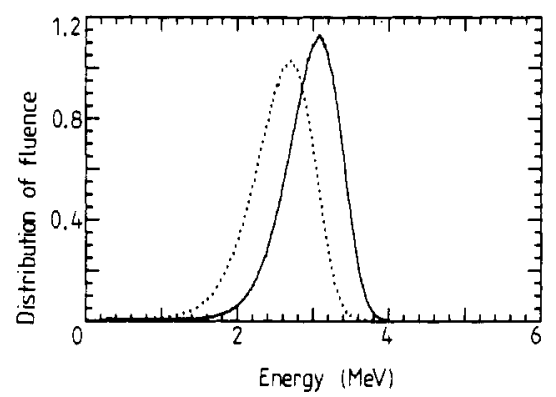

Figure 7. Measured distribution of $\alpha$ particle fluence in energy after traversal of exit window (full curve) and after additional traversal of the $2 \mu \mathrm{m}$ mylar foil bottom of a culture dish (dotted curve).

\subsection{Depth dependence of particle fluence}

The particle fluence at specified depth is given in figure 8. Again the dependences are given for the beam emerging from the exit window (experiments with inverted plates, for example exposure of bacteria on the surface of an agar layer) and for the beam emerging from the bottom foil (experiments with the special dishes for exposure of mammalian cells). The remaining ranges are roughly $18 \mu \mathrm{m}$ and $15 \mu \mathrm{m}$ under the two different conditions.

\subsection{Dependence of absorbed dose on depth}

The dependence of absorbed dose on depth is given in figure 9, again for the two different cases. The increase of the absorbed dose in depth reflects predominantly the increasing LET with decreasing energy of the particles. 


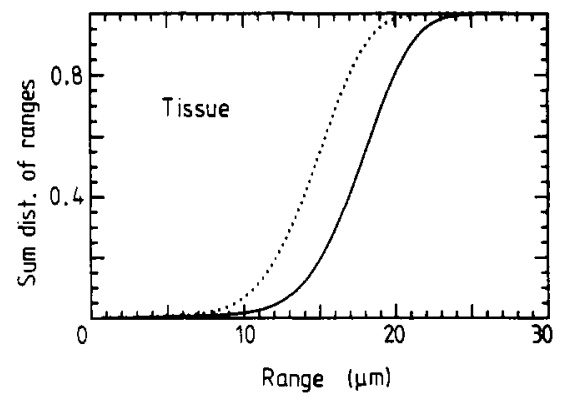

Figure 8. Sum distribution of remaining ranges in tissue for direct exposure of samples at the exit window (full curve) and within culture dishes (dotted curve).

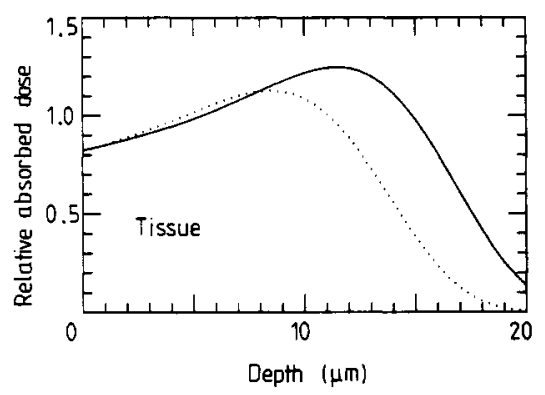

Figure 9. Absorbed dose against depth in tissue with direct exposure (full curve) and above the bottom foil of the culture dishes (dotted curve). The doses are scaled to the mean values up to depth $10 \mu \mathrm{m}$; the computations utilise values of LET in ICRU 36 (ICRU 1983).

\subsection{Compensation of the depth dependence of absorbed dose}

In certain applications it is desirable to achieve a more constant absorbed dose in the exposed sample than can be attained by a monoenergetic parallel beam of $\alpha$ particles. One must therefore ask whether a broader angular distribution or a broader energy distribution could attain this purpose. Computations for changed collimator designs have not suggested that the resulting changes of angular distribution are suitable. However, adequate approximations can be obtained by admixing a lower-energy component to the beam. Figure 10 shows the remarkably constant absorbed dose that

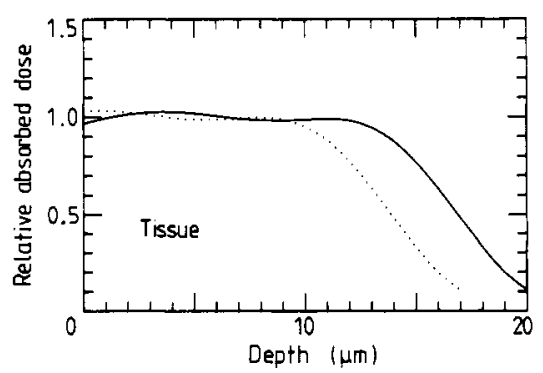

Figure 10. The dependences that result in the adjusted mode for direct exposure (full curve) and above the bottom foil of the culture dishes (dotted curve). 


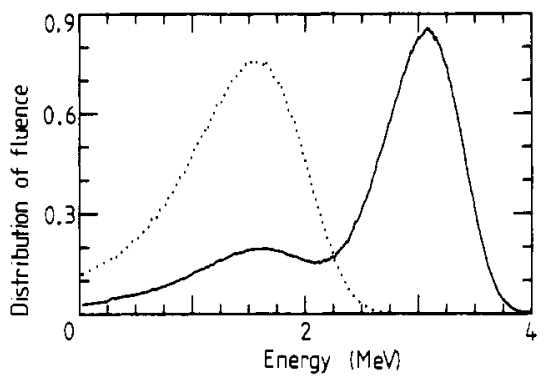

Figure 11. Measured distribution of fluence at the exit window with preabsorber (dotted curve). Distribution of fluence in the adjusted mode if the preabsorber is present for $25 \%$ of the total irradiation time (full curve).

is achieved by entering an $8 \mu \mathrm{m}$ mylar foil as preabsorber into the beam for $25 \%$ of the exposure time. The fluence distribution of the attenuated component is given in figure 11 as a dotted curve while the resulting composite fluence distribution is given as a full curve; these spectra need to be compared to the fluence distribution in figure 7. For the studies with mammalian cells the same arrangement can be utilised and the resulting absorbed dose distribution is given in figure 10 (dotted curve). The remaining plateau is sufficient for studies with mammalian cells adhering to the bottom foil.

\subsection{Dependence of the dose-averaged LET on depth}

Uniformity of absorbed dose is one desirable feature in the experiments, uniformity of LET is another, less critical condition. Owing to the slowing down of the $\alpha$ particles

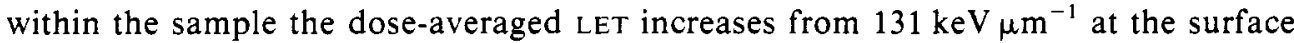
of the sample to a maximum value of $216 \mathrm{keV}_{\mu \mathrm{m}}^{-1}$ at a depth of $13.5 \mu \mathrm{m}$ if the sample is positioned immediately at the exit window (see figure 12, upper panel; the vertical bars indicate the standard deviations of LET).

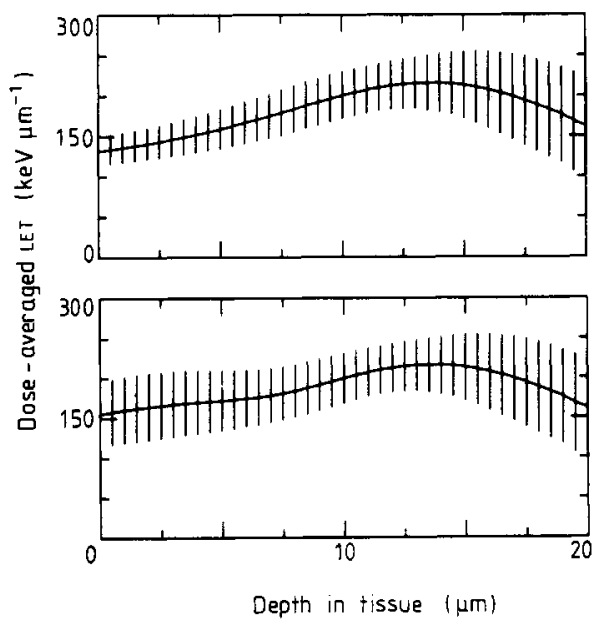

Figure 12. Dose-averaged LET as a function of depth in tissue for direct exposure at the exit window (upper panel) and for direct exposure in the adjusted mode (lower panel). The vertical bars represent the standard deviations. 
The adjusted mode of operation, i.e. the introduction of the preabsorber for $25 \%$ of the exposure time, increases the LET values near the surface and makes little difference for the LET values at larger depth. The dose-averaged LET is therefore somewhat more constant throughout the whole range. However, it is also evident that the admixture of less energetic $\alpha$ particles broadens the LET distribution (see figure 12, lower panel).

\section{Conclusion}

Cell studies with $\alpha$ emitters are a comparatively simple alternative to the use of heavy ion accelerators. They offer a much more narrow range of exposure parameters but permit far more controlled laboratory conditions for the experimental work. In cell studies this can be highly critical and it is therefore essential that an $\alpha$ irradiator be designed to provide exposures with well defined and suitably chosen exposure parameters. The present work documents a design which should be useful in a variety of experiments and has already been employed in studies with mammalian cells and bacteria that required a high degree of accuracy and reproducibility (Hieber et al 1987, Roos et al 1988).

The $\alpha$ irradiator provides a broad and highly uniform beam of $\alpha$ particles. The employment of a preabsorber foil during part of the exposures leads to a very nearly uniform absorbed dose throughout a layer of $12.5 \mu \mathrm{m}$ of the exposed sample. Hyperfractionation schemes that are equivalent to continual exposures with different dose rates and arbitrary fraction patterns can be obtained and are computer controlled. The dose rate of up to $0.2 \mathrm{~Gy} \mathrm{~min}^{-1}$ is sufficient for many cell studies. It can be increased by the employment of less narrow collimators.

\section{Acknowledgments}

The valuable technical help of Mr E Pfister, Mr J Fleder and Mrs B Meiers is gratefully acknowledged. This work has been supported by Research Grant BI-6-0013-D (B) from Euratom and by the Deutsche Forschungsgemeinschaft through SFB 172 at the University of Würzburg.

\section{Résumé}

Critères de conception et performances d'un appareil d'irradiation $\alpha$ pour les études des cellules.

Les auteurs décrivent un appareil d'irradiation $\alpha$ utilisant une source d'américium 241 se présentant sous la forme d'un disque de $8 \mathrm{~cm}$ de diamètre disponible dans le commerce. Les particules $\alpha$ passent dans un collimateur mobile et la source tourne sur elle-même pour réduire l'influence des inhomogénéités de source. La source, le collimateur et un disque obturateur sont placés dans une enceinte où circule de l'hélium pour réduire les pertes d'énergie des particules $\alpha$ avant que celles-ci n'atteignent la feuille de sortie. Le disque obturateur est déplacé par un moteur pas à pas contrôlé par ordinateur. Le faisceau large de particules $\alpha$ emerge de la fenêtre de sortie de l'enceinte avec un parcours résiduel dans les tissus d'environ $15 \mu \mathrm{m}$. L'utilisation d'un préabsorbeur commandé par ordinateur de façon intermittente a permis de réduire les différences de dose sur une épaisseur de $12,5 \mu \mathrm{m}$ à moins de $\pm 3 \%$. Un débit de dose de $0,2 \mathrm{~Gy} \mathrm{~min}^{-1}$ est obtenu avec les sources d'américium disponibles dans le commerce; une valeur plus élevée peut être atteinte en utilisant un collimateur légèrement plus large.

\section{Zusammenfassung}

Designkriterien und Betriebsparameter einer Alpha-Bestrahlungsvorrichtung für Zellstudien.

Es wird eine $\alpha$-Bestrahlungsvorrichtung beschrieben, die eine kommerziell erhältliche Am-241 Quelle (Durchmesser $8 \mathrm{~cm}$ ) nutzt. Die $\alpha$-Teilchen durchlaufen einen sich bewegenden Kollimator; die Quelle wird 
rotiert um den Einfluß ihrer Inhomogenitäten zu reduzieren. Quelle, Kollimator und eine Verschluß-Scheibe sind in einem Behälter eingebaut, der mit Helium gespült wird um den Energieverlust der $\alpha$. Teilchen auf dem Weg zum Austrittsfenster zu reduzieren. Der Verschluß wird durch einen rechnergesteuerten Schrittmotor betätigt. Ein ausgedehnter Strahl von $\alpha$-Teilchen, mit einer Restreichweite in Gewebe von etwa $15 \mu \mathrm{m}$, verläßt den Behälter durch das Austrittsfenster. Durch den rechnergesteuerten intermittierenden Einsatz eines Vorabsorbers können die Dosisunterschiede bis zu einer Tiefe von $12.5 \mu \mathrm{m}$ kleiner als $\pm 3 \%$ gehalten werden. Mit kommerziellen Ameriziumquellen ergibt sich eine Dosisleistung von $0.2 \mathrm{~Gy} \mathrm{~min}^{-1}$; durch die Verwendung eines weniger engen Kollimators kann die Dosisleistung erhöht werden.

\section{References}

Barendsen G W and Beusker T L J 1960 Effects of different ionizing radiations on human cells in tissue culture. I. Irradiation techniques and dosimetry Radiat. Res. $13832-40$

Barendsen G W, Walter H M D, Fowler J F and Bewley D K 1963 Effects of different ionizing radiations on human cells in tissue culture. III. Experiments with cyclotron-accelerated alpha-particles and deuterons Radiat. Res. 18 106-19

Edwards A A, Purrot R J, Prosser J S and Lloyd D C 1980 The induction of chromosome aberration in human lymphocytes by alpha-radiation Int. J. Radiat. Biol. 38 83-91

Elkind M M and Beam C A 1955 Variation of the biological effectiveness of X-rays and $\alpha$-particles on haploid Saccharomyces cerevisiae Radiat. Res. 3 88-104

Hall E J, Gross W, Dvorak R F, Kellerer A M and Rossi H H 1972 Survival curves and age response functions for Chinese hamster cells exposed to X-rays or high LET alpha-particles Radiat. Res. 52 88-98

Hieber L, Ponsel G, Roos H, Fenn S, Fromke E and Kellerer A M 1987 Absence of a dose-rate effect in the transformation of $\mathrm{C} 3 \mathrm{H} 10 \mathrm{~T} 1 / 2$ cells by $\alpha$-particles Int. J. Radiat. Biol. 52 859-69

ICRU 1983 Microdosimetry ICRU Report 36 (Bethesda, MD: ICRU)

Lea D E, Haines R B and Coulson C A 1936 The mechanism of the bactericidal action of radioactive radiations Proc. $R$. Soc. B120 47-76

Lloyd E L, Gemmell M A, Henning C B, Gemmell D S and Zabransky B J 1979 Transformation of mammalian cells by $\alpha$-particles Int. J. Radiat. Biol. 36 467-78

Lücke-Huhle C, Comper W, Hieber L and Pech M 1982 Comparative study of G2 delay and survival after ${ }^{241}$ Americium- $\alpha$ and ${ }^{60}$ Cobalt- $\gamma$-irradiation Radiat. Environ. Biophys. 20 171-85

Raju M R, Tobey R A, Jett J H and Walters R A 1975 Age response for line CHO Chinese hamster cells exposed to $\mathrm{X}$-irradiation and alpha particles from plutonium Radiat. Res. 63 422-33

Robertson J B, Koehler A, George J and Little J B 1983 Oncogenic transformation of mouse Balb/3T3 cells by plutonium-238 $\alpha$-particles Radiat. Res. 96 261-74

Roos H, Thomas W-H, Fitzek M and Kellerer A M $1988 \mathrm{His}^{+}$reversions caused in Salmonella typhimurium by different types of ionizing radiation Radiat. Res. 116 292-304

Thacker J, Stretch A and Goodhead D T 1982 The mutagenicity of $\alpha$-particles from plutonium-238 Radiat. Res. 92 343-52 